TRADUÇÃO, AUTORIA E ORIGINAL: POTÊNCIAS DO RIZOMA.

TRANSLATION, AUTHORSHIP AND ORIGINAL: POWERS OF THE RHIZOME.

Gilles Jean Abes

Universidade Federal de Santa Catarina Florianópolis, Santa Catarina, Brasil

RESUMO: O polêmico embate entre as visões opostas de Rosemary Arrojo e Paulo Henriques Britto, no campo da tradução, é exemplar na forma como se tem polarizado tentativas de subtrair tradutor e tradução a uma situação de subalternidade. Dessa dicotomia decorre com frequência a desvalorização de um dos lados a fim de legitimar o outro. Assim, neste artigo, objetivo uma alternativa a essa situação. Nesse sentido, inicio uma reflexão com base nas experiências de Carlos Drummond de Andrade, Charles Baudelaire e Paulo Henriques Britto, enquanto poetas e tradutores, buscando investigar a noção de autoria e debater o que se entende por original e tradução. Finalmente, procuro apontar uma vereda possível para evitar posições binárias: autor versus tradutor, original versus tradução. Proponho aqui debater esses termos empregando o conceito de rizoma, alocando tanto o original quanto o texto traduzido nessa rede assistemática, de proliferação horizontal, que possibilita a compreensão de relações não hierárquicas, assim como a inclusão do percurso por vezes caótico de obras como, por exemplo, os chamados "clássicos".

PALAVRAS-CHAVE: Tradução; Autoria; Original; Rizoma

ABSTRACT: The polemical clash between the opposing views of Rosemary Arrojo and Paulo Henriques Britto in the field of translation is exemplary in the way in which attempts have been made to subtract translator and translation from subalternity. This dichotomy often leads to the devaluation of one side in order to legitimize the other. Thus, in this article, I aim at an alternative to this situation. In this sense, I begin a reflection based on the experiences of Carlos Drummond de Andrade, Charles Baudelaire and Paulo Henriques Britto, as poets and translators, seeking to investigate the notion of authorship 
and discuss what is meant by original and translation. Finally, I try to point out a possible path to avoid binary positions: author versus translator, original versus translation. I propose here to discuss these terms using the concept of rhizome, allocating both the original and the translated text in this unsystematic network of horizontal proliferation, which enables the understanding of nonhierarchical relationships, as well as the inclusion of the sometimes chaotic path of works such as the so-called "classics".

KEYWORDS: Translation; Authorship; Original; Rhizome 
O presente artigo ${ }^{1}$ surgiu a partir de vários questionamentos: ao entender tradutor versus autor, tradução versus original, nessa dicotomia, estaríamos comparando objetos e sujeitos que pertencem à mesma instância? Ao querer valorizar a tarefa do tradutor, desejo legítimo e necessário, não estaríamos projetando a nossa reflexão na direção errada? É desvalorizando o original (texto fonte) e o autor que alcançaremos o reconhecimento da tradução e do tradutor? Quais são as relações entre o original e a tradução? Como dar visibilidade à tradução e ao tradutor evitando a hierarquia e sem perder os contornos do texto traduzido, em outras palavras, sem cair no relativismo? Se tomarmos o exemplo das obras consideradas "clássicas", não esquecemos seu percurso por vezes caótico antes que sejam assim nomeadas? Podemos avaliar objetivamente uma tradução, como sugere Paulo Henriques Britto?

Ao elencar essas dúvidas, objetivo repensar os papéis do autor e do tradutor, assim como, traçar as relações entre os textos fonte e meta, e suas potencialidades. Além disso, pretendo sobretudo apontar outra vereda possível para refletir sobre estas relações de modo não hierárquico.

\section{A POLÊMICA}

No Brasil, é exemplar dessa dicotomia um embate simbólico de opiniões no campo dos Estudos da Tradução entre Paulo Henriques Britto e Rosemary Arrojo, sobretudo na questão do reconhecimento/visibilidade do tradutor, ou ainda sobre o conceito de fidelidade, o que levou a uma discussão sobre a autoria - do autor e do tradutor -, o original e a tradução. Da mesma forma, o debate se deu sobre a possibilidade de avaliar objetivamente uma tradução e atribuir-lhe um valor. De Arrojo, vejam, por exemplo, o artigo "O tradutor 'invisível' por ele mesmo: Paulo Henriques Britto entre a humildade e a onipotência", publicado em 2000. O título já é bastante explícito sobre esse desentendimento. De Britto, observem os artigos "Desconstruir para quê?", de 2001, ou ainda "As condições de trabalho do tradutor", de 2007, e sobretudo, seu livro A tradução literária, de 2012, que trata principalmente dessa questão na primeira parte intitulada "Algumas considerações teóricas".

Segundo Britto, na proposta de Arrojo, há certo grau de radicalismo na forma como aborda autor e tradutor, chegando a uma depreciação do original. Depreciação, quer dizer aqui relativizar a importância do original de forma exacerbada ou até mesmo apagar essa noção de original. Sem esses conceitos, restariam apenas textos passíveis de múltiplas leituras (interpretações) livres de qualquer critério objetivo.

Britto concorda que não podemos identificar a intenção do autor, como não é possível defender a sua genialidade romântica. Todavia, ele não subscreve ao

\footnotetext{
${ }^{1}$ Este artigo é uma versão aprofundada de duas comunicações realizadas na ABRALIC e na UFC, em 2016, cujos títulos eram "O tradutor não é o autor" e "O tradutor é o autor? Autoria, tradução e original".
} 
relativismo agudo à qual, segundo ele, a reflexão de Arrojo (e de muitos outros teóricos) leva. É como se houvesse a necessidade de declarar novamente a morte do autor e do original, para finalmente obter o reconhecimento da tradução e de seu mestre. Britto não aceita esta inversão autoral e depreciação do original, e tenta explicar a diferença entre essas instâncias e processos. Ele afirma que o reconhecimento do tradutor deve se dar nos paratextos e em lutas por melhorias financeiras, como por exemplo, os direitos autorais. Arrojo discorda dessa visão e afirma a visibilidade do tradutor já nas suas escolhas tradutórias e até certa supremacia da tradução e do tradutor.

Em suma, para ela, a voz do tradutor deve aparecer na sua tradução, que deve se libertar do texto fonte, já que não se pode determinar objetivamente o seu valor e seu sentido, tampouco julgar a qualidade de traduções de um mesmo poema. Britto, por sua vez, critica essa posição teórica que ele qualifica de "radical". Defende que juízos de valor são possíveis, e que mesmo se o significado é uma propriedade instável, é preciso partir de uma noção não essencialista do significado e de sentidos pressupostos para realizar a tradução.

Britto sustenta que a tradução e a criação literária não são a mesma coisa; que o conceito de fidelidade ao original é de importância central na tradução; e que não só podemos como devemos avaliar criticamente traduções com um certo grau de objetividade (BRITTO, 2012, p. 27-28). O tradutor deve produzir um texto que possa ser lido como "a mesma coisa" que o original e, assim sendo, deve reproduzir os efeitos de sentido, de estilo, de som e ritmo, entre outros elementos, permitindo que o leitor da tradução afirma, sem mentir, que leu o original. (ibid, p. 28) Para Britto, apoiando-se em Jiří Levý e Anthony Pym, as traduções visam representar uma obra literária para leitores que não dominam o idioma em que ela foi escrita. Nesse sentido, sente-se um verdadeiro leitor de Kafka ao tê-lo lido nas traduções de Modesto Carone e testou essa reflexão quando defendeu suas posições em relação à obra kafkiana com argumentos que não pareceram descabidos para pessoas que o leram em alemão. Para ele, não se trata de compreender o sentido dentro de uma visão essencialista, mas de simplesmente respeitar as convenções do que se entende por tradução na sociedade e no tempo em que vivemos.

É impossível não levar em conta as contribuições do pós-estruturalismo, dos estudos culturais, dos estudos de gênero ou ainda do pós-colonialismo, a riqueza de leituras críticas das obras decorrentes de novas métodos de interpretação, a abertura para outras vozes e literaturas até então caladas, as discussões sobre as influências do Estado e das instituições sobre a formação do cânone, a história do livro e das políticas editorias, da censura e circulação clandestina de obras e assim por diante; na tradução, o seu papel, a visibilidade e a voz do tradutor, aliás, voz que está sempre presente em menor ou maior grau em qualquer tradução, com a influência de suas ideologias e crenças. Todavia, as colocações do Paulo Henriques Britto, assim como o lugar peculiar que ocupa poeta, tradutor, professor, pensador pragmático da tradução - não podem ser simplesmente rechaçadas ou tratadas como simples "onipotência", como sugere Arrojo no título do seu artigo acima mencionado. 


\section{SOBRE A OBJETIVIDADE E A LITERATURA}

No decorrer de uma de duas comunicações realizadas em congressos, que formam o alicerce deste artigo, um grande estudioso de literatura e tradução afirmou de forma contundente, e como que definitiva, que a literatura é o que uma comunidade decidiu ser literatura. Não há como discordar. Mas seria apenas isso? Podemos simplesmente afirmar que Shakespeare é o que é hoje por causa da política colonialista da Inglaterra? Ou as instituições britânicas se apoderaram da obra para usá-la como símbolo nacional de superioridade cultural? Refiro-me aqui à sua imposição como leitura obrigatória nas escolas e a uma imagem prédefinida de um Shakespeare que pretendiam moldar e divulgar. A importância de um autor é consequência exclusiva de uma imposição politico-cultural ou colonialista? Outro exemplo, Victor Hugo é lido apenas porque está enterrado no Panteão em Paris e porque o Estado francês fez dele um patrimônio, símbolo dos ideais republicanos?

Se não há como negar essas forças coercitivas, estas não formam completamente o que são as obras de autores como Shakespeare e Victor Hugo, para citar apenas estes. Acredito que o percurso das obras é bastante heterogêneo e depende de vários elementos. De fato, o sucesso de vendas, a eleição para uma Academia de Letras e até mesmo prêmios, como o Nobel de literatura ou o Jabuti, não são uma garantia da pervivência de um(a) autor(a) e de sua obra. Basta uma rápida consulta às listas de acadêmicos e dos laureados do Nobel para perceber que as instituições podem decidir o que é literatura, não obstante, não garantem que perdurem no tempo como obras lidas. Quem lê hoje Frédéric Mistral, que recebeu o prêmio Nobel em 1904, ou Maxime Du Camp, eleito à Academia Francesa de Letras no dia 26 de fevereiro de 1880 na cadeira de Saint-René Taillandier? Ainda mais se pensarmos além das fronteiras francesas, nome e obra se esvanecem. Por outro lado, a leitura obrigatória, na escola, provoca com frequência o efeito contrário quando não preconceitos em relação a autores e autoras. Pensem em Machado de Assis. O sucesso de vendas tampouco garante a longevidade da obra: quem lê hoje Eugène Sue na França? Não se trata de discutir se estas obras merecem ou não serem lidas e de problematizar os critérios de avaliação das Academias.

Antes, tenho dúvidas se a afirmação daquele especialista renomado constitui uma resposta satisfatória. Ao contrário, no fundo, aponta para uma questão inicial, e que talvez constitua a pedra de toque das posições divergentes de Arrojo e Britto, que é a do uso da razão para realizar uma interpretação objetiva de um texto, e a inescapabilidade da valoração.

Segundo Fábio Durão, em seu livro O que é a crítica literária? (2016):

A descrição do texto é apenas um momento da prática crítica, e a distinção entre bom e ruim, acertado e equivocado, é inevitável. Recusar-se a emitir um valor já equivale a defender um valor, a saber, o da ausência de valores. (p. 14-15) 
Mais adiante, Durão acrescenta que

será difícil para algum crítico negar pura e simplesmente a genialidade de Shakespeare. Sua grandiosidade está atestada em milhares de interpretações de suas peças e de sua lírica, que se estendem por séculos e fazem parte da herança histórica e cultural do ocidente. (p. 15)

Durão contrapõe ainda que

é importante perceber que mesmo o lugar dos maiores gênios da literatura não está assegurado. No decorrer da história, houve variações imensas de juízos (no século XVIII francês, Shakespeare era considerado um escritor bárbaro, e não sem razão), e quando a crítica não consegue mais apontar para algo de verdadeiramente novo e interessante em determinado autor, não importa o quão famoso seja, ele morre como objeto literário digno de nota. (p. 16)

Bastante instigante, nas palavras do professor de crítica literária, é o fato de empregar vocábulos como "genialidade" e "grandiosidade", assim como Britto emprega o termo "original", sem usar as aspas que são tão comuns nos trabalhos acadêmicos com seus sinônimos "texto fonte" e "texto de partida". De nada adianta forjar conceitos vazios de função e significado, criando em suma um linguajar acadêmico inoperante e até embaraçoso, para valorar o ofício do tradutor e o novo objeto que produziu. No fundo, o problema é muito menos a palavra em si, do que a maneira como é empregada, a propriedade com a qual é usada. Certamente, nem Durão, nem Britto empregam-nas no sentido do Romantismo, como criação total, pura, decorrente da genialidade individual do autor. O que Durão talvez queira dizer é de que não se pode negar, apesar de suas influências, de suas leituras e mestres, de que há efetivamente, por parte do autor ou autora, um trabalho de composição da obra, verdadeira tarefa de artesão que exige reflexão e certo grau de singularidade. Singularidade não no sentido da imitação, mas da emulação, nem tanto na ideia de superação de modelos, antes no estímulo que as leituras produzem no escritor. ${ }^{2}$

Além disso, se não alcançamos a intenção dos autores, e que o sentido e a interpretação (ou análise) da obra é instável, passível de leituras críticas fundadas em bibliotecas diversas, leituras que podem, portanto, variar consideravelmente, inclusive, oriundas do mesmo leitor em diferentes épocas de sua vida, no momento em que interpretamos ou criticamos um texto, somos levados a eleger um sentido e características temporariamente estáveis, com base em uma reflexão minimamente objetiva, o que é a grande diferença entre opinar e interpretar, ao menos no ambiente acadêmico. Não se trata de uma essência do texto, mas antes de conseguir cinzelar seus contornos, mesmo que estes sejam móveis, nas mãos de valores também cambiantes para diferentes épocas, sociedades e indivíduos.

\footnotetext{
${ }^{2}$ Ver a respeito o artigo "Imitação, emulação, modelos e glosa", de Thiago Saltarelli. Aletria, n. especial, 2009, p. 251-264.
} 
Arriscaria até dizer que a crise da qual vem sofrendo a literatura não é estranha a essa confusão entre opinião e interpretação. Se não há como delinear contornos do que é o literário, em suas formas diversas, como valorar tal objeto difuso para a sociedade, como justificar seu ensino e importância?

\section{DA EXPERIÊNCIA SINGULAR DE POETAS-TRADUTORES}

Entendo essa noção no sentido de Antoine Berman, em seu livro $A$ tradução e a letra ou o albergue do longínquo, que a formulou com base em Heidegger. Refiro-me à experiência da tradução - e da composição de uma obra original - e à tradução dessa experiência. De maneira mais específica, busca-se interpretar um acontecimento singular e o lugar de fala do poeta-tradutor (ou autor-tradutor). Esta dupla atividade deve, neste caso, ser assimilada como fazer uma experiência, fazer no sentido em que por ela se passa e se sofre. O sujeito acolhe e se submete a esse fazer. É o discurso produzido a partir dessa experiência que se procura analisar. Como diz Berman, "a tradução é uma experiência que pode se abrir e se (re)encontrar na reflexão". (BERMAN, 2013, p. 23)

Inicio essa reflexão com citações de Charles Baudelaire e Carlos Drummond de Andrade. O poeta itabirano fala sobre seu trabalho de traduzir $A s$ relações perigosas do Laclos. Baudelaire, por sua vez, nos trechos de duas cartas de 1865, comenta seu papel de tradutor de Edgar Allan Poe e também propõe a editores uma tradução da novela gótica Melmotho viajante, do autor irlandês Charles Maturin, publicada em 1820.

Ainda às voltas com a tradução de Les Liaisons Dangereuses, de Laclos, trabalho que empreendi pelo suposto prazer de traduzir, sem encomenda de editor. Que problema, escrever novamente um livro alheio! E que pretensão... Não sei o que mais padece neste jogo, se o pensamento do autor, se as palavras que o vestem. Para dizer a verdade, as traduções deviam ser proibidas, como moeda falsa. (ANDRADE, 2006, p. 29)

A Michel Lévy

[Bruxelas,] 15 de fevereiro de 1865.

[...] Não preciso dizer que não se trata de forma alguma de mim. Dediquei muito tempo a Edgar Poe porque ele se parece um pouco comigo. Eu não sou tradutor. 


\section{À Senhora Paul Meurice}

[Bruxelas.] Sábado 18 de fevereiro de 1865.

[...] eu me recordo perfeitamente de ter conversado, há oito meses, com Verboeckhoven sobre livros para ressuscitar. [...] Não me oferecia então como tradutor. Tenho receio dessas tarefas. Perdi muito tempo traduzindo Edgar Poe, e o grande benefício que tirei disso, foi que algumas boas línguas disseram que eu tomara emprestado a Poe minhas poesias, as quais estavam elaboradas dez anos antes que eu tivesse conhecido as obras dele.

Eu vejo as traduções como um meio de preguiçoso para bater moeda. (BAUDELAIRE, 2003, p. 326-330) ${ }^{3}$

Quando Drummond escreve esse comentário sobre sua tradução de Laclos, tem 42 anos, e como poeta, publicou Alguma poesia (1930), Brejo das almas (1934), Sentimento do mundo (1940), Poesias (1942 - 3 livros anteriores e "José"). De 1943 a 1945, está trabalhando no $A$ rosa do povo (1945). Como tradutor, publicou Uma gota de veneno, de François Mauriac (1943, Prêmio Nobel de Literatura em 1952). Apesar de sua aparente frustração com seu trabalho no romance epistolar de Laclos (1947), continuou traduzindo e publicando mais sete traduções até 1963: Os camponeses, de Balzac, em 1954; $A$ fugitiva, de Proust, em 1956; Dona Rosita, a solteira ou a linguagem das flores, de Lorca, em 1959; Jean-Théodore Descourtilz e seu Beija-Flores do Brasil, em 1960; O pássaro azul, de Maeterlinck, em 1962 (Prêmio Nobel de Literatura em 1911); Artimanhas de Scapino, de Molière, em 1962; e Fome, de Knut Hamsun, em 1963 (Prêmio Nobel de Literatura em 1920).

Quando escreve as cartas acima citadas, Baudelaire tem 43 anos, e como autor, publicou as edições de 1857 e 1861 de suas Flores do mal, assim como, em jornais, seus salões, parte de seus poemas em prosa, os Paraísos artificiais, a novela La Fanfarlo e alguns outros estudos. Como tradutor, dois anos antes, no dia $1^{\circ}$ de novembro de 1863, havia vendido, por 2.000 francos da época, os direitos dos seus cinco volumes de traduções de Edgar Allan Poe para o editor Michel Lévy.

A partir da experiência de Drummond e Baudelaire, enquanto poetastradutores, e de seus comentários, percebe-se certo mal-estar ou desconforto em relação à tradução (enquanto ofício e objeto) e no que diz respeito ao papel do tradutor. Drummond descreve o ofício como "escrever um livro alheio" e, diante das dificuldades, condena a tradução como "moeda falsa". Baudelaire, apesar de ter dedicado muito tempo à tradução de Edgar Poe e de sua tradução ter divulgado a obra e figura do autor americano, não se considera um tradutor. Novamente há uma analogia com a moeda, a tradução é vista como uma maneira fácil de "bater moeda", ou seja, fazer, produzir moedas (de ganhar dinheiro). Esses comentários, da parte de autores que já possuem certa experiência e

\footnotetext{
${ }^{3}$ Tradução de minha autoria. Grifos da edição dirigida por Claude Pichois.
} 
segurança em seu ofício, engendraram algumas interrogações: Qual é a origem dessa insegurança do tradutor?

Tomemos a experiência de outro poeta-tradutor, mas também professor que se posiciona teoricamente perante a tradução, Paulo Henriques Britto, a partir de sua obra $A$ tradução literária (2012). Talvez haja aqui um desfiladeiro a percorrer. No seu livro, Britto afirma, ao descrever a diferença entre os processos de composição de um poema seu e uma tradução de um poema de Wallace Stevens, também de sua autoria, o seguinte:

[...] tradução literária e criação literária não são a mesma coisa. Reconhecemos que a distinção entre as duas categorias é problemática, que há uma extensa zona cinzenta entre elas. (p. 33)

A sucessão dos rascunhos de meu poema demarcava uma trajetória centrífuga, em que eu conscientemente evitava uma proximidade excessiva em relação a diversos modelos literários, a fim de encontrar uma voz que me parecesse minha. Já as diferentes etapas da minha tradução de Stevens revelavam um processo centrípeto, em que eu evitava me afastar demais do texto original [...]. (p. 35)

O que interessa é explorar essa zona cinzenta, com uma mudança de perspectiva, complementar ou até mesmo ter uma ótica diversa. Ao meu ver, o caminho talvez seja não apenas observar diferenças durante e após a elaboração, ou ainda no produto final, como indica Britto, mas focar também o processo de composição/fabricação da tradução e da obra original em seu estágio inicial.

Busco nesse ponto afastar-me dessa zona cinzenta para encontrar um terreno mais firme. Para ilustrar essa diferença de ponto de partida, segue uma anedota de Paul Valéry, comentada por Manuel Bandeira:

Conta Valéry que certa vez o pintor Degas se queixou a Mallarmé de ter perdido o dia na vã tentativa de escrever um soneto. - No entanto, acrescentou, não são as ideias que me faltam... Tenho-as até demais. Ao que o mestre respondeu:-Mas, Degas, não é com ideias que se fazem versos: é com palavras. (2007, p. 116)

Haveria assim uma diferença processual entre autor e tradutor: ter como ponto de partida um conjunto de ideias abstratas, por um lado, ou por outro, palavras já estruturadas na forma de um texto. Essa diferença é a página branca. Deitar um universo, ainda disforme e impalpável na mente de um(a) autor(a), e traduzir um texto, são processos que têm por início pontos de partida distintos, mesmo se suas trajetórias terão em seguida muitos pontos de tangência. 


\section{TRADUÇÃO COMO SOBREVIDA, MOEDA FALSA E VARIANTE}

A partir dos discursos dos três autores-tradutores, resultado de sua experiência, vou apontar algumas pistas sobre as relações possíveis entre a tradução, tradutor e o original. Procurarei abordar e relacionar os conceitos de sobrevida (ou pervivência), moeda falsa e variante à tradução. Começo com a ideia de sobrevida, no famoso "A tarefa do tradutor", de Walter Benjamin.

A história das grandes obras de arte conhece sua descendência a partir das fontes, sua configuração na época do artista, e o período de sua pervivência, em princípio eterna, nas gerações posteriores. Quando surge, essa continuação da vida das obras recebe o nome de glória. Traduções que são algo mais do que meras transmissões surgem quando uma obra tiver chegado, na sua pervivência, à época de sua glória. Por isso, elas não estão tanto a serviço de sua glória (como costumam alegar os maus tradutores em favor de seu trabalho) quanto the devem sua existência. Nelas, a vida do original alcança, de maneira constantemente renovada, seu mais tardio e mais vasto desdobramento. (2010, p. 207-209)

Além da noção de sobrevida, a tradução é, ao meu ver, uma moeda falsa, como afirma Drummond, mas num sentido positivo. Para ilustrar a potencialidade dessa imagem, citamos justamente um poema em prosa de Baudelaire, publicado inicialmente em jornais e posteriormente no livro $O$ spleen de Paris, "A moeda falsa":

No meu miserável cérebro [...] entrou subitamente a ideia de que semelhante conduta, da parte do meu amigo, só era desculpável pelo desejo de criar um acontecimento na vida daquele pobrediabo, talvez até mesmo de saber as consequências diversas, funestas ou outras, que pode provocar uma moeda falsa nas mãos de um mendigo. Não poderia ela multiplicar-se em moedas verdadeiras? não poderia, também, levá-lo à prisão? Um taberneiro, um padeiro, por exemplo, talvez mandasse prendê-lo como moedeiro falso ou como passador de falsa moeda. De igual modo a moeda falsa talvez viesse a ser, para um pobre pequeno especulador, o germe de uma riqueza de alguns dias. E assim minha fantasia prosseguia, emprestando asas ao espírito de meu amigo e tirando todas as deduções possíveis de todas as hipóteses possíveis. $^{3}$

O que é afinal essa moeda falsa? Ao contrário dos dois poetas-tradutores, entendo aqui profanar essa analogia e propor uma imagem positiva da tradução. Entendo o termo "falsa" no campo lexical da música: Falsa - Dissonância -

\footnotetext{
${ }^{3}$ Tradução de minha autoria, com base na edição da Pléiade, de 1975, das obras completas de Baudelaire.
} 
Sucessão de sons desarmoniosos (desconcerto) - Desarmonia - Não conformidade - Dissonância do texto fonte.

Como explica Walter Costa, Borges, de maneira quase oposta a Britto, enxerga o original como apenas mais uma versão no supratexto formado pelas suas diversas leituras das traduções de uma mesma obra. Há, nessas variantes de leituras, potencialização da tradução enquanto objeto e processo de leitura crítica.

Enquanto muitos escritores modernos provavelmente não leram sequer uma versão desses livros, Borges leu atentamente varias versões deles em inglês, francês e alemão. Através dessas várias reescritas ele chega a uma espécie de supratexto dessas obras e pode imaginar as variantes possíveis, inclusive as variantes virtualmente produzidas por um leitor (ou ouvinte) grego de Homero ou de língua árabe do texto das Mil e uma noites. Através da leitura incessante de múltiplas traduções é criada uma instancia transcendente, da qual o original passa a ser apenas uma versão, embora a primeira do processo. (COSTA, 2005, p. 171)

A tradução é, portanto, variante do original, que forma com o conjunto das outras traduções, um poderoso supratexto de leituras críticas.

\section{O ORIGINAL COMO CLÁSSICO}

Se relacionar, de maneira mais estreita, essas ideias de variante e dissonância abordadas na seção anterior, ao original, poder-se-ia melhor compreender o quão importa é a relação de interdependência entre, por exemplo, um texto considerado clássico, e a tradução.

Antoine Compagnon procura estabelecer uma definição do "clássico" que parece pertinente, sobretudo se associarmos à sua reflexão as de Durão, Benjamin, Borges e a tradução entendida como moeda falsa (dissonância). Ao tomar o romance proustiano como, ao mesmo tempo, exemplo da prosa clássica francesa do século $\mathrm{XX}$, e como texto não adequado às definições do que seria uma obra clássica, Compagnon chega à seguinte consideração:

Assim, se Proust é aos meus olhos um clássico, e até mesmo o clássico, não é, ou não somente, no sentido do cânone, da sala de aula, do panteão escolar e universitário, e também não é, ou tão pouco, no sentido do classicismo histórico, como busca pela ordem, equilíbrio, reserva, apagamento. Mas é no sentido em que cada geração renova a significação e o alcance dessa obra, enriquece-a, dela toma posse, sem dúvida porque essa obra não é perfeita, não é fechada sobre ela mesma, não é concluída: [...]. (2011, p. 04-05)

\footnotetext{
${ }^{4}$ Tradução de minha autoria. Ensaio disponível no site do Collège de France pelo link: $<$ https://www.college-de-france.fr/site/antoine-compagnon/articles_en ligne.htm $>$.
}

Acesso em 30 mar. 2017. 
Há, nessa tentativa de definição do clássico, um elemento que é pertinente para essa reflexão. $O$ fato de não haver garantia de uma obra perdurar no tempo, como bem lembrou Durão e o destaque para a interdependência entre a pervivência dos textos escritos e os leitores.

\section{POTÊNCIAS DO RIZOMA}

Uma vereda possível, para evitar posições binárias e hierárquicas entre autor e tradutor, original e tradução, inscrevendo simultaneamente suas complexas e imprevisíveis relações, seria entender toda essa rede de conexões dentro da lógica do rizoma. Ao alocar tanto o original quanto o texto traduzido nessa rede assistemática, de inter-relação horizontal, possibilitar-se-ia a sua compreensão de uma forma não hierárquica, assim como a inclusão do percurso por vezes caótico de obras, o passado, por exemplo, dos chamados "clássicos"sua história, feita também do acaso, não somente da apropriação comercial e patrimonial - e o caminho percorrido pelas suas variantes e outros epitextos: as traduções e sua fortuna crítica. De fato, o que se entende por acaso ou percurso caótico, é a trajetória sinuosa de certos manuscritos de autores considerados clássicos da literatura ocidental. Proust é um deles. Mesmo oferecendo-se para pagar a publicação do primeiro volume do Em busca do tempo perdido, o romance No caminho de Swann, o autor sofreu várias recusas, inclusive, a da Gallimard, sendo o principal responsável o também autor André Gide. O arrependimento será imenso por parte de Gide que perceberá mais tarde o equívoco. Outras casos não faltam, como Franz Kafka, cuja obra poderia ter sido destruída se não fosse a desobediência de seu amigo Max Brod, ou ainda, Faulkner ou Orwell, entre tantos outros autores e autoras. No caso de Proust, sua convicção na obra e sua condição financeira foram fatores determinantes para que não abandonasse a publicação. Cabe ainda pensar na evolução das obras na forma como foram ganhando importância, por vezes esquecidas ou menosprezadas durante longos períodos, caso do próprio Shakespeare na França, ou ainda de François Rabelais ou do Marquês de Sade. Quem lê atualmente o romance Viagem ao fim da noite, de Louis-Ferdinand Céline, sobretudo na França? A associação da obra com o passado do autor, considerado antissemita e que teria colaborado com os nazistas durante a ocupação, muito prejudicou a importância dos aportes de sua prosa inovadora. Há leitores, mas muitos se recusam a lê-lo pelos motivos aqui expostos. Os exemplos são numerosos e não cabe elencar todos eles, mas chamar a atenção para esse passado tumultuoso.

A ideia é simplesmente de tentar dar espaço a esse percurso caótico. Conforme os filósofos Gilles Deleuze e Félix Gattari, as características do rizoma seriam as seguintes: 
Resumamos os principais caracteres de um rizoma: diferentemente das árvores ou de suas raízes, o rizoma conecta um ponto qualquer com outro ponto qualquer e cada um de seus traços não remete necessariamente a traços de mesma natureza; [...] Ele não tem começo nem fim, mas sempre um meio pelo qual ele cresce e transborda. [...] Uma tal multiplicidade não varia suas dimensões sem mudar de natureza nela mesma e se metamorfosear. Oposto a uma estrutura, que se define por um conjunto de pontos e posições, por correlações binárias entre estes pontos e relações biunívocas entre estas posições, o rizoma é feito somente de linhas: linhas de segmentaridade, de estratificação, como dimensões, mas também linha de fuga ou de desterritorialização como dimensão máxima segundo a qual, em seguindo-a, a multiplicidade se metamorfoseia, mudando de natureza. [...] O rizoma procede por variação, expansão, conquista, captura, picada. Oposto ao grafismo, ao desenho ou à fotografia, oposto aos decalques, o rizoma se refere a um mapa que deve ser produzido, construído, sempre desmontável, conectável, reversível, modificável, com múltiplas entradas e saídas, com suas linhas de fuga. (1995, p. 31-32)

O rizoma é, na verdade, um tipo de raiz que se desenvolve horizontalmente, daí o interesse em transformá-lo em conceito por evitar a hierarquia da árvore que se fixa a partir de um ponto. Os princípios de conexão e heterogeneidade também são fundamentais para compreender essa vida singular dos textos. As relações tornam-se múltiplas, não são mais correlações binárias, são como fibras nervosas que se expandem sem direção exata. Os traços do rizoma conectam pontos que não são da mesma natureza (adaptações, reencenações, experimentos tradutórios) e seguem ampliando-se, por variação.

\section{CONSIDERAÇÕES}

Em suma, mesma se a maneira de enxergar a tradução de Paulo Henriques Britto se restringe e se estabelece a partir de um lugar de fala muito específico - o do tradutor que precisa ser pragmático e trabalha para a publicação de traduções literárias em grandes editoras - deve-se pensar na questão da análise objetiva e da impossibilidade de escapar a algum tipo de julgamento de valor perante um texto, seja este uma tradução ou não, como também afirma Durão. Da mesma forma, o fato de não existir apenas um original de Hamlet, não invalida a ideia de original ou de texto fonte. Como lembra Chartier, "a genealogia da autoria é mais antiga do que Foucault pensava" (2012, p. 62), começa a surgir aos poucos já em meados do século XV, e não no final do século XVIII (como disse Foucault). Com efeito, naquele período, vários mecanismos reforçaram a emergência da "função-autor", considerando-se apenas os escritores literários, não os textos que chamaríamos hoje de científicos. Chartier identifica uma ação contra um impressor que havia publicado o texto sem o consentimento de seu autor, já em 
1504. Há, portanto, neste gesto, uma tentativa de controle da obra. O próprio Index da igreja católica necessitava da identificação dos autores, para controlar a circulação dos livros e textos, sob diferentes formas. Existiam simplesmente outras formas de identificação. A autoria podia ser mais claramente divulgada nas folhas de rosto e colofões, com retratos do próprio autor ou autora, por vezes representado compondo sua obra.

Chartier aponta duas formas de direitos autorais, principalmente com base nas pesquisas de Mark Rose: o direito de propriedade do autor no sentido de controlar a publicação de seus textos a fim de preservar sua privacidade e reputação e o direito de propriedade do autor entendido como um interesse econômico em um bem alienável. O primeiro seria o que Mark Rose chama de propriety, o outro property. No caso da propriety, era uma forma de lutar contra as edições piratas, de baixa qualidade, que "manchavam" a honra dos autores. Um caso citado é o de Lope de Vega que teria protestado contra estas edições de suas comédias, não somente corrompendo suas peças, mas também atribuindo-lhe peças supostamente ruins que ele jamais escrevera (ibid, p. 51-52). Além disso, a autoria podia ser apontada de diferentes formas, não apenas na folha de rosto, como em cartas, elogios, listas de autores, ou ainda listas de obras proibidas caso da inquisição.

Por outro lado, é evidente que quanto mais recuarmos no tempo, tanto mais tenderemos a encontrar obras elaboradas, com diferentes versões, muito antes da existência de edições impressas, caso dos textos de tradição oral, como a Odisseia. Antes interessa integrar esse passado do texto-fonte - sua história - não somente em suas variações (edições, manuscritos), mas igualmente em seu percurso por vezes caótico cuja própria existência pode ter dependido do acaso, de uma insistência do autor, de um gesto de preservação, do incentivo de um amigo, ou ainda, do interesse de um desconhecido. Ao adentrarmos uma biblioteca e deambularmos por entre aqueles clássicos empoeirados, esquecemos da história que antecedeu sua glória, quando eram apenas manuscritos nas mãos angustiadas de autores e autoras.

Finalizando, o tradutor se apropria de um texto alheio, com maior ou menor liberdade em função de seu projeto de tradução, texto outro que carrega obrigatoriamente sua voz, pois foi por ele composto. De maneira mais precisa, quando um escritor passa a traduzir - casos de Britto, Baudelaire e Drummond -, muda de posição e se instala em outra instância criadora. Os processos de criação centrífugo e centrípeto podem apontar trajetórias processuais diversas, todavia, se sobrepõem dado o movimento de afastamento e reaproximação (do texto fonte) que é por vezes necessário para atingir e recriar a literariedade, a letra, o tom, o outro do original. Seria eficiente, para dar visibilidade ao tradutor, criar um conceito para destacar a sua autoria? Tenho dúvidas que tal conceito dê visibilidade ao tradutor. Talvez o caminho seja realmente o dos paratextos, como disse Britto e o da conscientização para exigir melhorias nos direitos e na remuneração.

De qualquer forma, o tradutor, ao bater a moeda falsa, não deve ser visto como um falsário/traidor - pois forçosamente produz um outro texto -, mas como um artesão da palavra que potencializa a obra original, ampliando, ramificando, 
desviando o texto num sistema rizomático no qual não há hierarquia, não há contorno rígido, antes pode haver multiplicidade, transgressão, desdobramento, releitura, apropriação, recriação, reimaginação, reencenação, experimento, performance, e assim por diante. Finalmente, com essa proliferação, a tradução ressuscita o texto - original ou uma tradução anterior -, pode até torná-lo um clássico ou reanimar sua glória, lembrando aqui de Benjamin, insuflar-lhe uma sobrevida. Pode inclusive prejudicar a obra original e o autor, ao simplificá-los. É o caso de La Fontaine no Brasil, por exemplo.

Em suma, o tradutor não é o autor. O tradutor é um autor que reescreve um texto alheio, novo texto que passa a ser também seu. E a tradução, como a moeda falsa no poema de Baudelaire, é uma verdadeira máquina de produzir acontecimentos.

\section{REFERÊNCIAS}

ANDRADE, Carlos Drummond de. O observador no escritório. Rio de Janeiro: Record, 2006.

ARROJO, Rosemary. 'O tradutor 'invisível' por ele mesmo: Paulo Henriques Britto entre a humildade e a onipotência". In: Trabalhos em lingüística aplicada, v. 36,2000 , p. 159-165.

BANDEIRA, Manuel. Seleta em prosa e verso. Organização Emanuel de Moraes. $6^{a}$ ed. Rio de Janeiro: José Olympio, 2007.

BAUDELAIRE, Charles. Correspondance. Choix et présentation de Claude Pichois et Jérôme Thélot. Paris: Gallimard, 2003.

. Oeuvres complètes. - Paris: Gallimard, 1975.

BENJAMIN, Walter. "A tarefa do tradutor". In: HEIDERMANN, Werner (Org.). Clássicos da teoria da tradução. Florianópolis: UFSC/Núcleo de Pesquisas em Literatura e Tradução, 2010.

BRITTO, Paulo H. A tradução literária. Rio de Janeiro: Civilização Brasileira, 2012.

$41-50$.

. "Desconstruir para quê?". In: Cadernos de Tradução, v. 2, n. 8, 2001, p.

"As condições de trabalho do tradutor". In: Cadernos de Tradução, v. $1 \mathrm{n}$. 19, 2007, p. 193-204.

CHARTIER, Roger, FAULHABER, Priscila., LOPES, José Sérgio Leite. (orgs). Autoria e história cultural da ciência. Rio de Janeiro: Beco do Azougue, 2012. $160 \mathrm{p}$. 
COMPAGNON, Antoine. "Le classique" (26/02/2011). Acesso em 14 set. 2016. Disponível em: $<$ https://www.college-de-france.fr/site/antoinecompagnon/articles en ligne.htm>

COSTA, Walter C. "Borges, o original da tradução.". In: Cadernos de Tradução, v. 1, n. 15,2005 , p. 187-210.

DELEUZE, Gilles.; GATTARI, Félix. Mil platôs - capitalismo e esquizofrenia, vol. 1. Tradução Aurélio Guerra Neto e Célia Pinto Costa. Rio de Janeiro: Ed. 34, 1995.

DERRIDA, Jacques. Donner le temps- 1. La fausse monnaie. Paris: Éditions Galilée, 1991.

DURÃO, Fábio Akcelrud. $O$ que é crítica literária? 1. ed. São Paulo: Nankin editorial, Parábola editorial, 2016.

FALEIROS, Álvaro. Traduzir o poema. Cotia, SP: Ateliê Editorial, 2012.

SALTARELLI, Thiago. "Imitação, emulação, modelos e glosa" In: Aletria, n. especial, jul.-dez. 2009, p. 251-264.

Gilles Jean Abes GillesUFSC@gmail.com

Recebido em: 5/9/2017

Aceito em: 14/2/2018

Publicado em Abril de 2018 